\title{
RESEARCH
}

\section{Partial lipodystrophy with severe insulin resistance and adult progeria Werner syndrome}

Bruno Donadille ${ }^{1}$, Pascal D’Anella ${ }^{2}$, Martine Auclair ${ }^{3,4,5}$, Nancy Uhrhammer $^{6}$, Marc Sorel ${ }^{7}$, Romulus Grigorescu ${ }^{8}$, Sophie Ouzounian ${ }^{1}$, Gilles Cambonie ${ }^{9}$, Pierre Boulot ${ }^{10}$, Pascal Laforêt $^{11}$, Bruno Carbonne ${ }^{12}$, Sophie Christin-Maitre ${ }^{1,13}$, Yves-Jean Bignon ${ }^{6}$ and Corinne Vigouroux ${ }^{1,3,4,5,14^{*}}$

\begin{abstract}
Background: Laminopathies, due to mutations in $L M N A$, encoding A type-lamins, can lead to premature ageing and/or lipodystrophic syndromes, showing that these diseases could have close physiopathological relationships. We show here that lipodystrophy and extreme insulin resistance can also reveal the adult progeria Werner syndrome linked to mutations in WRN, encoding a RecQ DNA helicase.

Methods: We analysed the clinical and biological features of two women, aged 32 and 36, referred for partial lipodystrophic syndrome which led to the molecular diagnosis of Werner syndrome. Cultured skin fibroblasts from one patient were studied.

Results: Two normal-weighted women presented with a partial lipodystrophic syndrome with hypertriglyceridemia and liver steatosis. One of them had also diabetes. Both patients showed a peculiar, striking lipodystrophic phenotype with subcutaneous lipoatrophy of the four limbs contrasting with truncal and abdominal fat accumulation. Their oral glucose tolerance tests showed extremely high levels of insulinemia, revealing major insulin resistance. Low serum levels of sex-hormone binding globulin and adiponectin suggested a post-receptor insulin signalling defect. Other clinical features included bilateral cataracts, greying hair and distal skin atrophy. We observed biallelic WRN null mutations in both women (p.Q748X homozygous, and compound heterozygous p. Q1257X/p.M1329fs). Their fertility was decreased, with preserved menstrual cycles and normal follicle-stimulating hormone levels ruling out premature ovarian failure. However undetectable anti-müllerian hormone and inhibin B indicated diminished follicular ovarian reserve. Insulin-resistance linked ovarian hyperandrogenism could also contribute to decreased fertility, and the two patients became pregnant after initiation of insulin-sensitizers (metformin). Both pregnancies were complicated by severe cervical incompetence, leading to the preterm birth of a healthy newborn in one case, but to a second trimester-abortion in the other. WRN-mutated fibroblasts showed oxidative stress, increased lamin B1 expression, nuclear dysmorphies and premature senescence.

Conclusions: We show here for the first time that partial lipodystrophy with severe insulin resistance can reveal WRN-linked premature aging syndrome. Increased expression of lamin B1 with altered lamina architecture observed in WRN-mutated fibroblasts could contribute to premature cellular senescence. Primary alterations in DNA replication and/or repair should be considered as possible causes of lipodystrophic syndromes.
\end{abstract}

Keywords: Lipodystrophy, Insulin resistance, WRN gene, Premature aging, Progeria, Pregnancy, Decreased ovarian reserve, Cervical insufficiency, Prelamin A, Lamin B1

\footnotetext{
* Correspondence: corinne.vigouroux@inserm.fr

${ }^{1}$ Assistance Publique-Hôpitaux de Paris (AP-HP), Hôpital Saint-Antoine,

Endocrinologie, Diabétologie et Endocrinologie de la Reproduction, F-75012,

Paris, France

${ }^{3}$ INSERM UMR_S938, Centre de Recherche Saint-Antoine, F-75012, Paris,

France

Full list of author information is available at the end of the article
}

\section{Biomed Central}

(c) 2013 Donadille et al.; licensee BioMed Central Ltd. This is an Open Access article distributed under the terms of the Creative Commons Attribution License (http://creativecommons.org/licenses/by/2.0), which permits unrestricted use, distribution, and reproduction in any medium, provided the original work is properly cited. 


\section{Background}

The studies of clinical and cellular consequences of LMNA mutations in humans have provided several indications of a close physiopathological relationship between premature aging and lipodystrophic syndromes. Indeed, human naturally-occuring LMNA mutations, among other phenotypes of laminopathies, have been shown to be responsible for premature ageing syndromes (HutchinsonGilford progeria, HGPS, and mandibuloacral dysplasia, MAD) [1-4], lipodystrophic syndromes (familial partial lipodystrophy of the Dunnigan type, FPLD2) [5,6], and mixed phenotypes [7-10]. At the cellular level, a highly similar disorganization of the nuclear lamina is observed in fibroblasts from patients with FPLD2, MAD and HGPS $[3,11,12]$, including cellular replicative senescence and prelamin A accumulation [13-15]. Although the pathophysiological mechanisms leading to $L M N A$-linked premature aging are not fully understood, a major hypothesis is that alterations in maturation and farnesylation of lamin A induce genomic instability, abnormal epigenetic control of heterochromatin and DNA damage responses, and mesenchymal stem cell defects [16-18].

Werner syndrome (WS) is an autosomal recessive premature aging syndrome due to biallelic inactivating mutations in WRN, encoding a RecQ DNA helicase/exonuclease involved in DNA replication and repair [19]. Its prominent features, occurring after adolescence, associate "bird-like" facies, scleroderma-like skin changes with tight and atrophic skin, bilateral cataracts, short stature and premature greying of scalp hair [20]. An initial clinical presentation as a lipodystrophic syndrome has not been previously described.

In women with familial partial lipodystrophies, decreased fertility and obstetrical complications have been reported to be mainly linked to insulin resistance and metabolic disturbances, with an increased prevalence of polycystic ovary syndrome, gestational diabetes and eclampsia [21,22]. The mechanisms leading to decreased fertility in Werner syndrome have not been deciphered. Only rare cases of pregnancies have been reported in women with probable, but not genetically-confirmed Werner syndrome [23-26].

Here we report the cases of two women investigated for lipodystrophy and severe insulin resistance, which revealed Werner syndrome due to homozygous or compound heterozygous, non-sense or frameshift mutations in the WRN gene. The two patients became pregnant after initiation of metformin therapy. Both pregnancies were complicated by cervical incompetence, leading to a second-trimester abortion in one case and to a preterm delivery in the other patient. Cultured fibroblasts obtained from one patient showed cellular senescence, nuclear dysmorphies, and lamin staining abnormalities similar to those found in laminopathies, but did not overexpress immature prelamin A.
Our study points out that primary defects in DNA replication and/or repair should be considered as possible causes of lipodystrophic syndromes with extreme insulin resistance. In addition, we show that cell nuclear dysmorphies with alterations in lamin staining can be secondary to cellular senescence of different origin.

\section{Patients and methods \\ Patients}

Two women of 32 and 36 years old were referred to us for partial lipodystrophic syndrome. Clinical, biological, molecular, and cellular studies were performed after full written informed consent, according to the ethic committee of Hôpital Saint-Antoine, in line with the Helsinki Declaration.

\section{Phenotype and genotype characterization}

Skinfolds thickness was measured using a Harpenden calliper. Routine serum measurements and 75g-oral glucose tolerance tests (OGTT) were performed after an overnight 12 -h fast. Serum adiponectin and leptin levels were determined by ELISA (Quantikine, R\&D Systems, Oxford, UK), on frozen-stored samples.

Genomic DNA from the two patients was extracted from peripheral blood leukocytes. The entire coding region and splice junctions of LMNA, PPARG and/or WRN were amplified and sequenced. DNA from patient 1's placenta and from foetal liver and muscular tissues was extracted for direct sequencing of exon 19 of the WRN gene.

\section{Cellular studies \\ Cell cultures}

Primary fibroblast cultures were established after skin biopsies in patient 1 and in two control women aged 20 and 33, without known disease, who underwent cosmetic surgery. Fibroblasts were grown in DMEM medium $\left(\right.$ Gibco $^{\circ}$ Cell Culture, Invitrogen Corporation, San Diego, CA, USA) containing $1 \mathrm{~g} / \mathrm{L}$ glucose, $20 \mathrm{mM}$ L-glutamine, $25 \mathrm{mM}$ Hepes, $110 \mathrm{mg} / \mathrm{ml}$ sodium pyruvate, $10 \%$ foetal bovine serum (FBS, Gibco), $100 \mathrm{U} / \mathrm{ml}$ penicillin and 0.1 $\mathrm{mg} / \mathrm{ml}$ streptomycin (Invitrogen Corporation) at $37^{\circ} \mathrm{C}$ in 5\% CO2/95\% air.

\section{Western blot analysis}

Western blot analyses were performed on whole cell extracts using antibodies directed against lamin-A/C (MAB3211, Chemicon International Inc. Temecula, CA, USA), total prelamin-A (SC-6214, Santa Cruz Biotechnology, CA, USA), or uncleaved prelamin-A isoforms (i.e., containing the CSIM C-terminal aminoacids, farnesylated or not) (ANT0045, 1188-1, Diatheva, Fano, Italy) [27], lamin B1 (ab16048, Abcam, Cambridge, UK) and betaactin (A5441; Sigma-Aldrich, Saint-Louis, MO, USA). 


\section{Cell morphology and immunofluorescence microscopy}

Immunofluorescence studies were performed on fibroblasts grown on glass coverslips after fixation in methanol at $-20^{\circ} \mathrm{C}$, as previously described [15]. DAPI (4,6'-diamidine-2-phenylindole dihydrochloride) was used for nuclear staining. Antibodies directed against lamin-A/C (MAB-3211) and B type-lamins (a generous gift from JC. Courvalin and B. Buendia, Institut Jacques Monod, France $[11,28]$ ) were revealed by using secondary antibodies coupled to Texas Red or CyTM2 (Jackson Immuno Research Laboratories, West Grove, PA, USA). A total of 350 to 550 nuclei was examined and counted for each subject. Images were acquired and processed using Adobe Photoshop software after visualisation by conventional microscopy.

\section{Reactive Oxygen Species (ROS) production}

We used the CM-H2DCFDA derivatives (5- (and 6)chloromethyl-2,7'-dichlorodihydrofluorescein diacetate, acetyl ester, C6827, Molecular Probes) as cell-permeant indicators of ROS [15]. Cells were cultured in 96-well plates, then washed and incubated with CM-H2DCFDA $(9 \mu \mathrm{M})$ or DAPI $(0.01 \mu \mathrm{g} / \mathrm{ml})$ in DMEM medium without FBS for $2 \mathrm{~h}$ at $37^{\circ} \mathrm{C}$ in the dark. Quantification, performed with a plate fluorescence reader (Spectrafluor Plus, Tecan-France, Trappes, France) at $520 \mathrm{~nm}$ (CM-H2DCFDA) or $465 \mathrm{~nm}$ (DAPI), was normalized to the DNA content.

\section{Senescence-associated beta-galactosidase assay}

Physiological lysosomal and senescence-associated betagalactosidase activities were assessed by cellular X-gal blue staining at $\mathrm{pH} 4$ and $\mathrm{pH} 6$, respectively. Cells were fixed for $10 \mathrm{~min}$ at $22^{\circ} \mathrm{C}$ with $2 \%$ formaldehyde $/ 0.2 \%$ glutaraldehyde, incubated overnight at $37^{\circ} \mathrm{C}$ in $1 \mathrm{mg} / \mathrm{ml} 5$-bromo4-chloro-3-indolyl- $\beta$-D-galactoside (X-gal), $40 \mathrm{mM}$ citric acid-sodium phosphate ( $\mathrm{pH} 6$ or 4), $5 \mathrm{mM}$ potassium ferricyanide, $5 \mathrm{mM}$ potassium ferrocyanide, $150 \mathrm{mM} \mathrm{NaCl}$ and $2 \mathrm{mM} \mathrm{MgCl}$, then lysed in $\mathrm{H}_{2} \mathrm{O}$ and sonicated. The blue X-gal cellular staining was quantified at $630 \mathrm{~nm}$. The ratio of $\mathrm{pH} 6$ to $\mathrm{pH}$ 4-staining specifically represented senescence-activated beta-galactosidase activity.

\section{Pathological and histological analyses}

Macroscopic analyses of placenta and foetus were performed two days after abortion. Light microscopy was performed on $10 \%$ formol-fixed paraffin-embedded 5-mm tissue sections, stained with hematoxylin-eosin.

\section{Statistical analyses}

All experiments were performed at least three times on triplicate samples. Quantitative results are expressed as mean \pm SEM. Comparisons between WRN-mutated and control cells were made with Student's t-test. $P$ values of less than 0.05 were considered significant.

\section{Results \\ Case reports \\ Patient 1}

A 32-year-old woman was referred to our Endocrinology Department for partial lipodystrophy. Her parents, without known consanguinity, originated from close villages of Madere Island, Portugal. Her medical history was uneventful until puberty, when she complained of myalgia during exercise. Pubertal development was normal with spontaneous menarche at age 11, followed by primary oligomenorrhea with menstrual cycles of 30 to 60 days. A first-trimester spontaneous miscarriage was reported at age 27. She had been treated a few months ago with amitryptiline then lamotrigine for painful peculiar peripheral neuropathy of the limbs (Sorel at al, manuscript in preparation). Physical examination showed lipoatrophy of the four limbs, including palms and soles, but sparing the face, and contrasting with truncal and abdominal subcutaneous fat accumulation (Figure 1). Peripheral lipoatrophy and central fat accumulation appeared progressively since puberty. Loss of muscle mass from the limbs was striking. Height was $158 \mathrm{~cm}$, weight $60 \mathrm{~kg}$ (body mass index, BMI: $24 \mathrm{~kg} / \mathrm{m}^{2}$ ), waist and hip perimeters 92 and $96 \mathrm{~cm}$, respectively. Skin examination revealed livedo reticularis, dry, tight and atrophied skin, petechiae, purpuric lesions and hyperkeratosis, predominant in the extremities (Figure 1). No acanthosis nigricans or hirsutism were observed. Blood pressure was 120/70 mmHg. Cardiac examination was normal. Further inquiry revealed that hair graying appeared since age 25 and surgical extraction of bilateral cataracts at age 26. Among the five siblings of the patient, a brother died at 44 years old from myocardial infarction; he was reported with dysmorphic features, premature cataracts, insulin-treated diabetes since age 26 , and severe atherosclerosis leading to foot amputation at age 38. A $42 \mathrm{yr}$-old sister died from sarcoma of the quadriceps femoris muscle.

Biological investigations revealed severe insulin resistance with moderate fasting hyperinsulinemia $(168 \mathrm{pmol} / \mathrm{L}$, normal value $<100$ ) reaching extremely high values after oral glucose tolerance test (OGTT) (maximal value 53800 $\mathrm{pmol} / \mathrm{L}$ at $\mathrm{T} 60 \mathrm{~min}$, then $29750 \mathrm{pmol} / \mathrm{L}$ at T120 min, normal $<520$ ), without altered glucose tolerance (Table 1 and Figure 2). Hypertriglyceridemia was associated with low HDL-cholesterol and slightly elevated alanine transaminase (ALT) and gamma-glutamyl transferase (GGT) levels. Sex-hormone binding globulin (SHBG) and adiponectin levels were low. Pituitary-ovarian functions and testosterone level were normal, but serum anti-müllerian hormone $(\mathrm{AMH})$ and inhibin $\mathrm{B}$ were not detectable, suggesting decreased ovarian reserve (Table 1). Pelvic and transvaginal sonography showed a normal uterus but enlarged ovaries (right : $6.2 \mathrm{~cm}^{2}$, left : $6.9 \mathrm{~cm}^{2}$, normal volume $<5.5 \mathrm{~cm}^{2}$ ) with follicules of 10.4 to $15.8 \mathrm{~mm}$. 

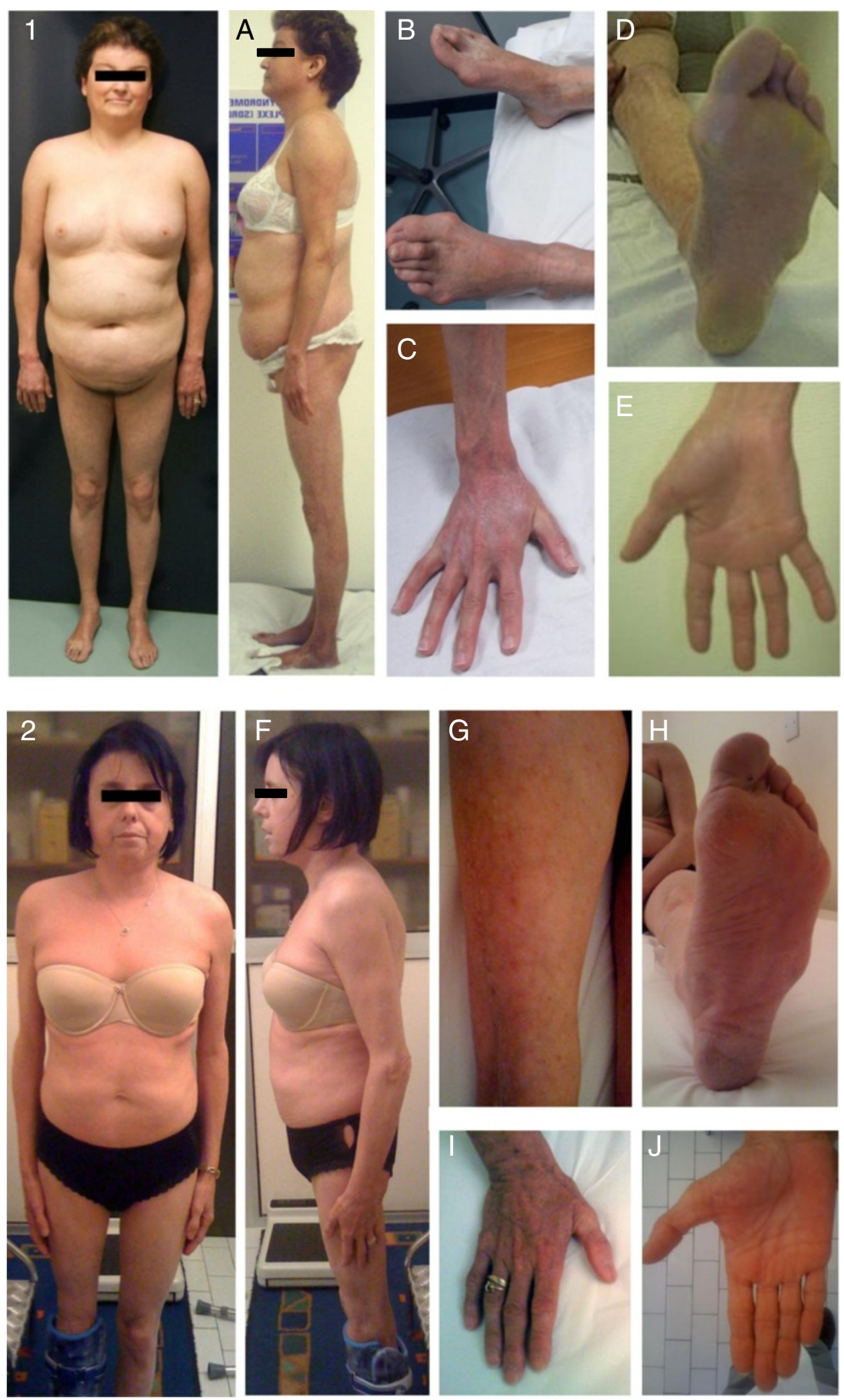

Figure 1 (See legend on next page.) 
(See figure on previous page.)

Figure 1 Clinical features of patients. Photographs of patient 1, aged $32(1, \mathbf{A}, \mathbf{B}, \mathbf{C}, \mathbf{D}, \mathbf{E})$ and patient 2, aged $36(2, \mathbf{F}, \mathbf{G}, \mathbf{H}, \mathbf{I}, \mathbf{J})$, showing partial lipodystrophy with subcutaneous fat accumulation of the trunk and abdomen with lipoatrophy of the limbs including palms and soles $(1, \mathbf{A}, \mathbf{B}, \mathbf{D}, \mathbf{C}, \mathbf{E})$, livedo reticularis of the limbs $(\mathbf{B}, \mathbf{D}, \mathbf{G})$, sclerodactylia $(\mathbf{C}, \mathbf{E}, \mathbf{I}, \mathbf{J})$, dry, tight and atrophic skin with hyperkeratosis of extremities $(B, C, D, E, H, I, J)$

Electrocardiogram and dipyridamole-thallium myocardial scintigraphy were normal, whereas doppler ultrasonography evidenced a mildly increased carotid intima-media thickness $(0.9 \mathrm{~mm}$, normal $<0.6 \mathrm{~mm})$. Other investigations revealed mild sensorineural hearing loss. A whole-body MRI did not reveal any neoplasm.

Peripheral lipoatrophy was quantified by skinfold thickness measurements (Figure 3A). Whole-body dualenergy X-ray absorptiometry (DEXA) revealed increased body fat, predominantly distributed in the trunk area, in accordance with the clinical findings (Figure 3B). Bone mineralization was normal. MRI imaging showed that peripheral lipoatrophy affected the four limbs (Figure 4A). In the thighs, subcutaneous fat was asymmetrically distributed, with normal medial but reduced postero-lateral adipose tissue (Figure 4A). MRI also showed a severe loss of gluteal fat and an increase in both subcutaneous and visceral abdominal fat depots

Table 1 Biological features of patients

\begin{tabular}{|c|c|c|c|}
\hline & Patient 1 & Patient 2 & Normal values \\
\hline Fasting glycemia (mmol/L) & 5.1 & 4.9 & $4-5.6$ \\
\hline Fasting insulinemia (pmol/L) & 168 & 371 & $13-100$ \\
\hline 2 h post-OGTT glycemia (mmol/L) & 6.5 & 12.2 & $4-7.4$ \\
\hline 2 h post-OGTT insulinemia (pmol/L) & 29750 & 8884 & $90-520$ \\
\hline $\mathrm{HbA1c}(\%)$ & 6.8 & 6.1 & $<5.5$ \\
\hline Total cholesterol (mmol/L) & 4.8 & 5.8 & $4-5.5$ \\
\hline LDL-cholesterol (mmol/L) & 3.6 & 3.5 & $1.2-4.1$ \\
\hline HDL-cholesterol (mmol/L) & 0.75 & 0.98 & $1-2$ \\
\hline Triglycerides (mmol/L) & 2.4 & 2.8 & $0.55-1.6$ \\
\hline Alanine transaminase (ALT) (IU/L) & 47 & 75 & $10-40$ \\
\hline Aspartate transaminase (AST) (IU/L) & 24 & 34 & $10-32$ \\
\hline Gamma-glutamyl transferase (GGT) (IU/L) & 60 & 113 & $8-54$ \\
\hline Leptin ( $\mu \mathrm{g} / \mathrm{L})$ & 33 & 8.6 & $2.4-25$ \\
\hline Adiponectin (mg/L) & 0.8 & 1.9 & 3.9-12.9 \\
\hline Sex-hormone binding globulin (nmol/L) & 14 & 16.1 & $40-80$ \\
\hline Insulin-like growth factor 1 (IGF-1) ( $\mu \mathrm{g} / \mathrm{L})$ & 166 & 313 & $175-375$ at age $30-40$ \\
\hline Thyroid stimulating hormone (TSH) (mU/L) & 4.8 & 3.8 & $0.8-4.8$ \\
\hline Free T4 ( $\mu \mathrm{g} / \mathrm{L})$ & 9.4 & 8.6 & 7.5-21.1 \\
\hline Follicle stimulating hormone (FSH) (IU/L) & 7.5 & 6.4 & $2-13$ \\
\hline Luteinizing hormone $(\mathrm{LH})(\mathrm{IU} / \mathrm{L})$ & 3.2 & 4.6 & $1.5-11$ \\
\hline Estradiol (pmol/L) & 215 & 480 & $80-370$ \\
\hline Total testosterone (nmol/L) & 0.96 & 1.7 & $0.3-1.85$ \\
\hline Androstenedione (nmol/L) & 4.9 & 13.5 & $2-11.4$ \\
\hline Dehydroepiandrosterone sulfate (mmol/L) & 2.4 & 1.8 & $0.9-11.6$ \\
\hline Prolactin $(\mu \mathrm{g} / \mathrm{L})$ & 6.6 & 5.4 & 3-27 \\
\hline Anti-Müllerian hormone (pmol/L) & $<0.3$ & $<0.3$ & $3.6-62$ \\
\hline Inhibin B (ng/L) & $<10$ & $<10$ & $60-125$ \\
\hline
\end{tabular}

OGTT oral glucose tolerance test.

Hormone measurements were performed in early follicular phase.

Anti-Müllerian hormone and inhibin B levels were measured at age 33 for patient 1 . 


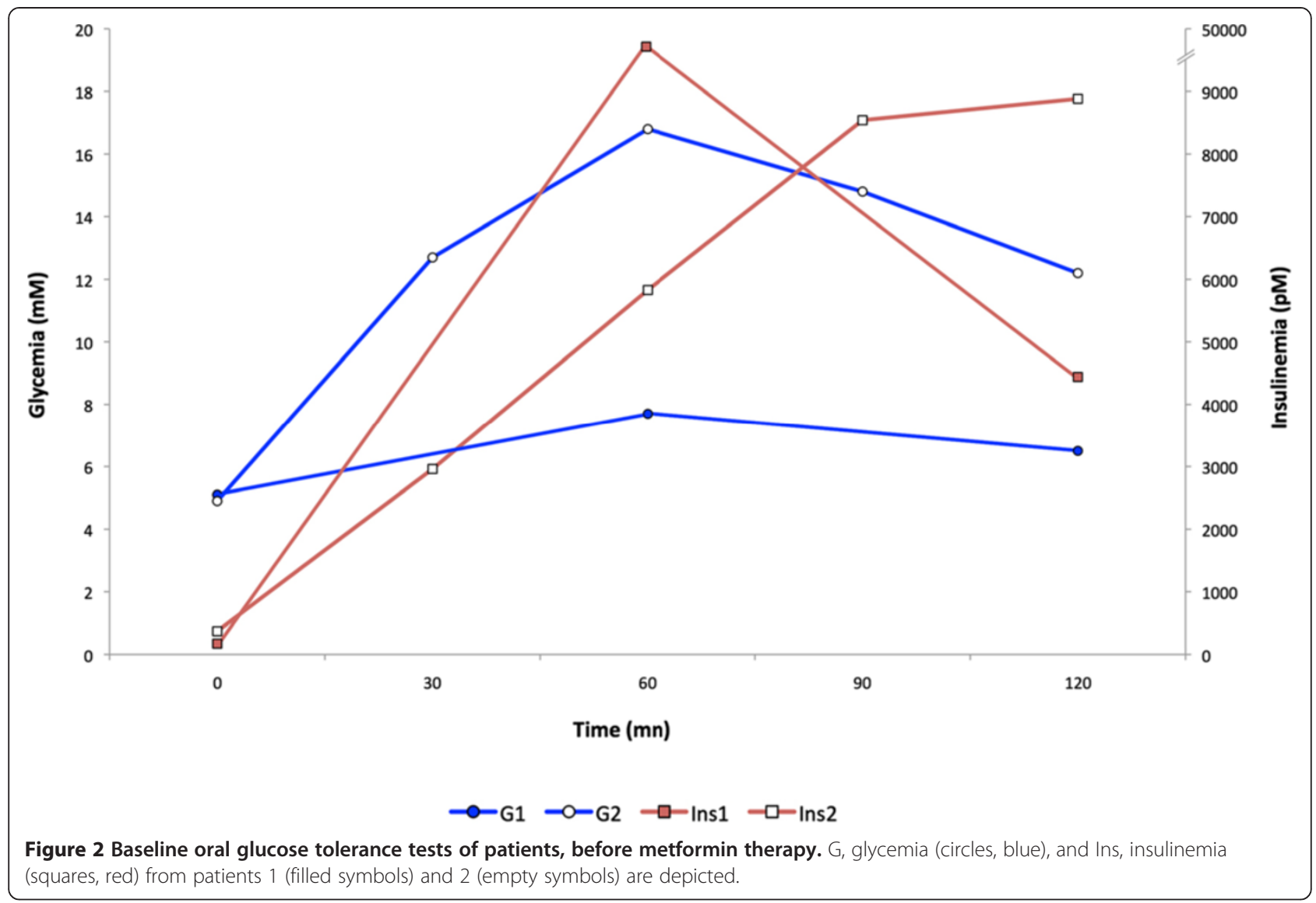

(Figure 4A and 4B). Imagery also revealed liver steatosis.

Sequencing of LMNA and PPARG did not reveal any alteration. WRN sequencing revealed homozygosity for a c. $2242 \mathrm{C}>\mathrm{T}$ transition in exon 19 , predicting the synthesis of a p.Q748X WRN protein, truncated in its helicase domain, which was absent in 100 unrelated control subjects.

Appropriate diet and metformin therapy decreased insulin resistance, although insulinemia remained elevated (respectively 130 and $1600 \mathrm{pmol} / \mathrm{l}$ at OGTT T0 and T120 min after three months, with normal glycemia). Statin and fibrate treatments were poorly tolerated, due to muscular pain.

One year later, after six years of infertility, the patient became spontaneously pregnant. She developed gestational diabetes, treated with diet and insulin. At 10 weeks of pregnancy, a short cervix $(18 \mathrm{~mm})$ was noted and a cervical cerclage was performed. Obstetrical ultrasound scan was normal at 16 weeks, but premature rupture of membranes, followed by spontaneous abortion occurred at 20 weeks of gestation. Pathological examination of the placenta showed signs of chorioamnionitis and funiculitis, which did not allow precise evaluation of possible previous vascular alterations (Figure 5A). The female foetus weighted $294 \mathrm{~g}$ (normal for gestational age), and showed a craniofacial dysmorphy associating retrognatism, receding forehead and flat nasal bridge, that could be linked to prolonged oligohydramnios due to premature rupture of membranes. X-ray analysis of the whole skeleton was normal. Foetal histopathological examination only revealed hyperplasia of pancreatic Langerhans islet cells (Figure 5B). Heterozygosity for the p.Q748X WRN mutation was observed in placental and foetal DNA.

\section{Patient 2}

A 36-year-old woman was referred for partial lipodystrophy. She was born from non-consanguineous healthy parents of Sicilian and French origin. Her two siblings, a 34-yr old sister and a 38-yr old brother, were also reported to be healthy. Her medical history was uneventful until age 30, when she underwent surgical removal of a chondrosarcoma of the right distal femur (with total knee prosthetic replacement). At this time a $2 \mathrm{~g} / \mathrm{l}$ fasting glycemia was observed, in the absence of antibodies directed against glutamic acid decarboxylase 65 and tyrosine phosphatase (anti-GAD and anti-IA2); BMI was $20.3 \mathrm{~kg} / \mathrm{m}^{2}$. Hypertriglyceridemia reached $4 \mathrm{~g} / \mathrm{l}$, and liver steatosis was 


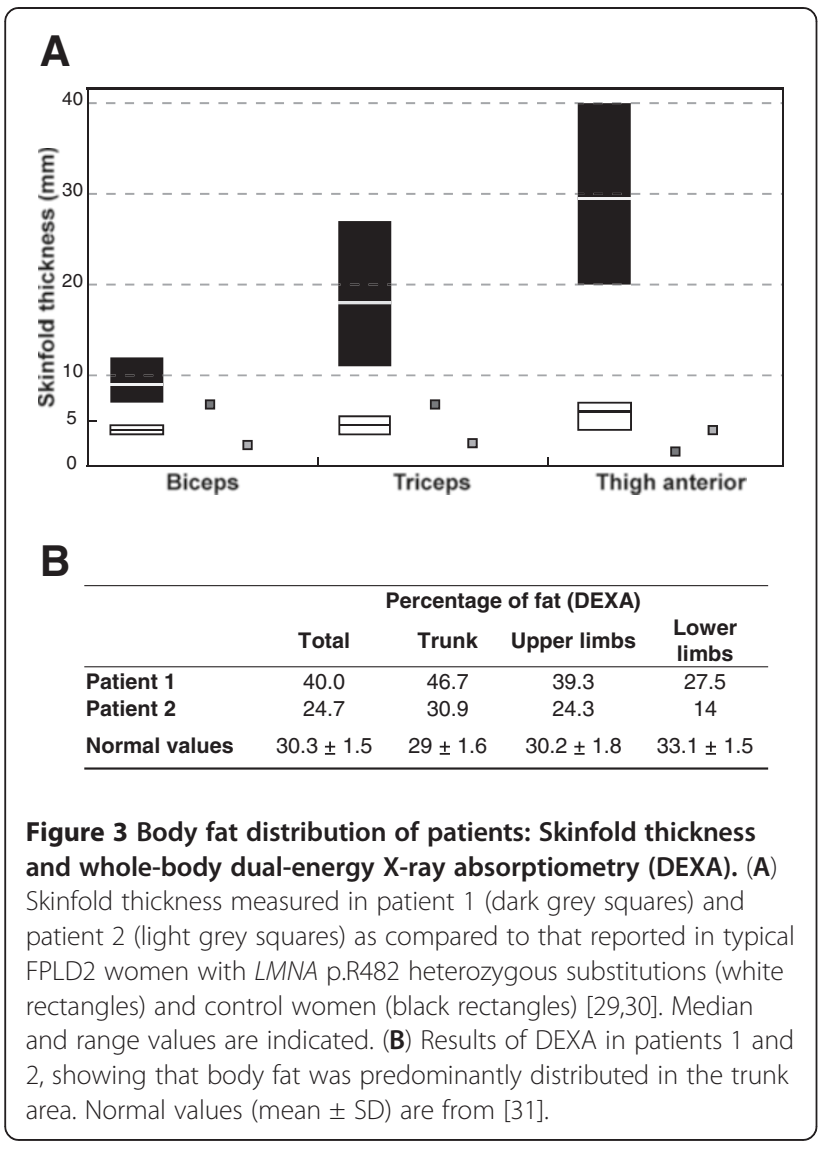

diagnosed on ultrasonographic appearance and elevated ALT and GGT in the absence of any other cause. Metabolic alterations were controlled using diet, fibrates and $\alpha$ glucosidase inhibitors. Regarding gynecological history, puberty was normal, with spontaneous menarche at age 11 , and regular menstrual cycles of 28 days. A firsttrimester spontaneous miscarriage was reported at age 34 . Since then, she did not conceive and consulted for 2 year infertility. At examination, she presented a partial lipodystrophy phenotype, with lipoatrophy and loss of muscle mass of the four limbs, palms and soles, which progressively appeared since age 20. Lipoatrophy spared the face, which contrasted with truncal and abdominal subcutaneous fat accumulation (Figure 1 and Figure 3A). Height was $144 \mathrm{~cm}$, weight $39 \mathrm{~kg}$ (BMI: $18.8 \mathrm{~kg} / \mathrm{m}^{2}$ ), waist and hip perimeters $76 \mathrm{~cm}$. A high-pitched voice was noted. Skin examination revealed livedo reticularis on the limbs, with dry, tight, atrophied skin and hyperkeratosis, predominant in the extremities (Figure 1). No acanthosis nigricans or hirsutism were observed. Blood pressure was 110/60 mmHg. Cardiac examination was normal but doppler monitoring revealed diffuse atherosclerosis. Further inquiry revealed that hair graying appeared since age 12, and bilateral cataracts were diagnosed at age 34 .
OGTT revealed severe hyperinsulinemia (fasting and T120 min values, 371 and $8884 \mathrm{pmol} / \mathrm{L}$, respectively) with diabetes (glycemia was normal at fast but reached 12.2 $\mathrm{mmol} / \mathrm{L}$ at T120 min OGTT) (Table 1 and Figure 2). Hypertriglyceridemia was associated with slightly low HDL-cholesterol and elevated ALT and GGT. Leptin was normal for BMI. SHBG and adiponectin levels were low. $\mathrm{FSH}$ and testosterone levels were normal, but $\mathrm{AMH}$ and inhibin B very low (Table 1).

Peripheral lipoatrophy was assessed by skinfold thickness measurements (Figure 3A) and by MRI imaging. As for patient 1 , MRI showed asymmetrical distribution of subcutaneous fat in the thighs and increased intra-abdominal fat stores (Figure 4). DEXA confirmed that fat was predominant in the trunk and reduced in the lower limbs (Figure 3B). Bone mineral density was low ( -2 and $-2.8 \mathrm{SD}$ at the vertebral and the femoral levels, respectively).

WRN sequencing revealed previously undescribed compound heterozygous mutations, with a c.3769C $>\mathrm{T}$ transition in exon 32 predicting a p.Q1257X truncation, and a c.3986delT frameshift deletion in exon 34 predicting the synthesis of a 1333 amino acid p.M1329fs WRN truncated protein, both mutated proteins lacking their nuclear localization signal. These mutations were absent in 100 unrelated control subjects.

Metformin was added to the treatment of the patient, and she became pregnant two months later. Insulin therapy was needed from the second month of pregnancy. A prophylactic cervical cerclage was performed at 15 weeks of gestation, but premature rupture of membranes with preterm labor occurred at 21 weeks. Treatment allowed the maintenance of pregnancy until 31 weeks, when a caesarean section was performed for chorioamnionitis. The patient gave birth to a healthy female child of $2310 \mathrm{~g}$ (normal for gestational age) with normal clinical examination except for the presence of a receding forehead without radiological signs of craniodysostosis. X-ray analysis of the whole skeleton, and cardiac and abdominal echography were normal. Placental histological examination confirmed the diagnosis of chorioamnionitis but did not reveal other specific alterations.

\section{Cell studies}

Primary fibroblast cultures from patient 1 were studied in comparison to control cells and/or to cells from a patient with FPLD2 due to the heterozygous p.R482W LMNA mutation [15], at the same passage.

\section{Fibroblasts from patient 1 showed nuclear shape abnormalities without altered expression and localization of type A lamins}

Nuclear shape abnormalities, with lobulations and blebs, were more prevalent in patient 1's than in controls' cells, studied at the same early passage (mean \pm SEM $: 18.4 \pm 4.1$ 


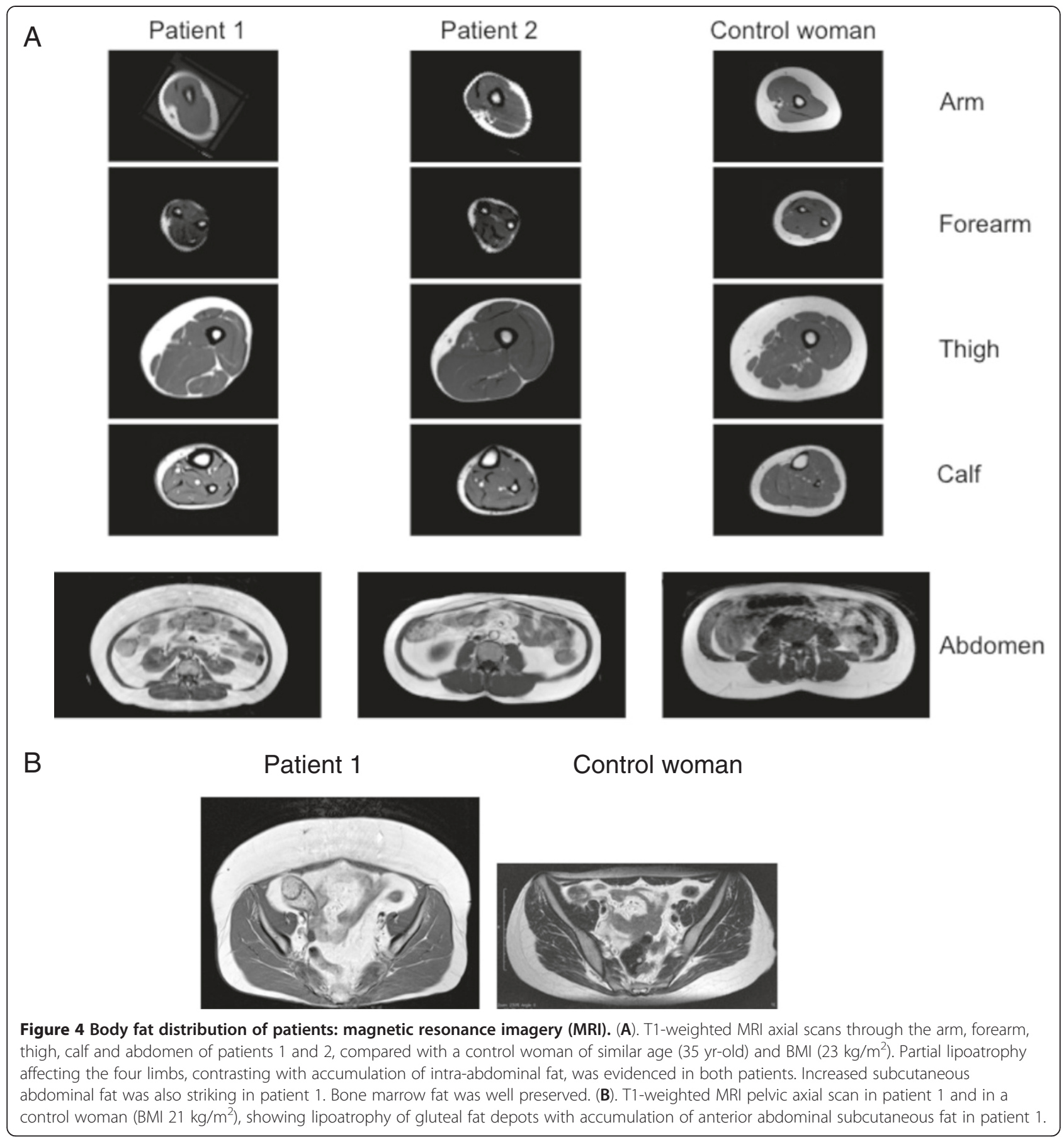

vs $3.4 \pm 3.2 \%$, respectively, $\mathrm{p}<0.001$ ). In addition, nuclear blebs showed altered lamin $\mathrm{A} / \mathrm{C}$ staining and were frequently devoid of lamin B, with a weak DNA staining suggesting chromatin decondensation, as shown by immunocytochemistry (Figure 6A). Protein expression of type A-lamins was not different, but lamin B1 levels were increased in fibroblasts from patient 1, as compared to control or LMNA p.R482W-mutated cells. Prelamin A, which is known to be accumulated in p.R482W LMNA- mutated cells [15], was not detectable in control and patient 1's cells (Figure 6B).

\section{Fibroblasts from patient 1 showed increased oxidative stress and premature senescence}

Oxidative stress, assessed by cellular ROS production, was increased in fibroblasts from patient 1 as compared to controls, at the same passage (Figure 6C). The WRN-mutated fibroblasts also prematurely acquired a senescence- 


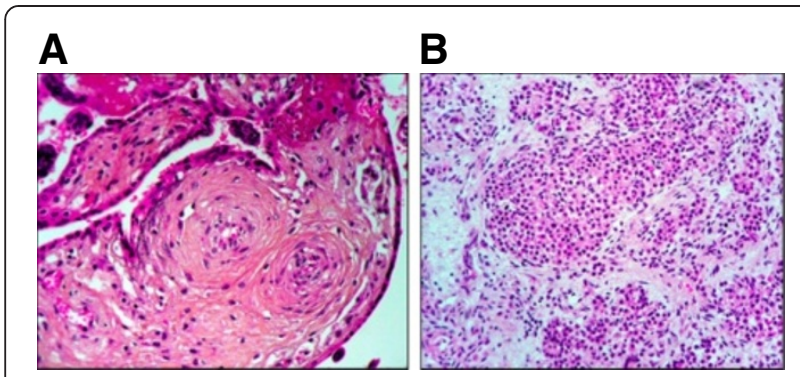

Figure 5 Pathological features of placenta and foetus from patient 1 (hematoxylin-eosin staining). (A) Placenta villosities examination. (B) Hyperplasia of Langerhans islet cells from the foetus's pancreas.

associated flattened and enlarged morphology in culture, and have a significantly increased senescence-associated ß-galactosidase activity, as compared to control cells of the same passage (Figure 6D).

\section{Discussion}

In the present study, we add further evidence for a pathophysiological link between cellular senescence and lipodystrophy, by showing for the first time that partial lipodystrophy syndrome with extreme insulin resistance can be the initial referring presentation of the adult progeria Werner syndrome, due to a primary defect in the WRN enzyme, involved in DNA replication and repair.

Lipodystrophic syndromes are heterogeneous diseases of genetic or acquired origin, characterized by generalized or partial lipoatrophy associated with insulin resistance. Recent advances in molecular genetics have shown that primary defects in fat differentiation and/or adipose lipid droplet formation or maintenance are the main causes of genetic lipodystrophies (for review, see [32-34]). However, the hypothesis that lipodystrophy could also be secondary to primary mesenchymal cellular senescence was raised by the studies of laminopathies, which collectively name a group of diseases due to alterations in the ubiquitous nuclear intermediate filaments A type-lamins, encoded by the $L M N A$ gene. Indeed, mutations in $L M N A$ can lead to Dunnigan-type familial partial lipodystrophy (FPLD2) [5,6], but also to accelerated ageing syndromes [1-4], and to mixed overlapping phenotypes with both lipoatrophy, metabolic complications and progeroid signs [7-10]. In addition, cellular studies have shown that, although lamin A alterations could impair adipogenesis through mislocalisation of the key adipogenic transcription factor SREBP1c [14,35-37], premature cellular senescence probably also participates to the pathophysiology of LMNAlinked lipodystrophy [15].

Werner syndrome, also called adult progeria (OMIM 277700), is one of several progeroid syndrome due to defective DNA helicases (for review, see [20]). This segmental aging syndrome, affecting several organ systems, is due to recessive null mutations in the WRN protein, which exhibits exonuclease, ATPase and helicase activities. Cellular senescence associated with Werner syndrome has been linked to DNA replication and repair defects [19]. The clinical diagnostic criteria have been defined by the International Registry of Werner Syndrome (http://www. wernersyndrome.org/registry/diagnostic.html) [20], and have been recently revised on the basis of the results of a Japanese nationwide epidemiological survey [38].

Both patients described here were referred for partial lipodystrophy, which is not listed as a classical sign of the disease. Several lipodystrophic features were different to those usually observed in other types of partial lipoatrophic syndromes, as FPLD2 or 3 due to LMNA or PPARG mutations, respectively. Indeed, in both patients, peripheral lipoatrophy was associated with loss of limb muscles, which contrasted with the muscle hypertrophy associated with FPLD2 and 3. In addition, marked central adiposity was striking, and imagery revealed an asymmetrical distribution of subcutaneous fat in the thighs. Both patients also exhibited several cardinal signs of Werner disease, i.e. bilateral cataracts, tight and atrophied skin with hyperkeratosis, and premature greying of scalp hair. In addition, patient 2 had short stature, and two siblings of patient 1 were probably affected, although molecular analysis was not possible. Further signs, listed as reminiscent of Werner disease, were also present: atherosclerosis and altered fertility in both cases, and highpitched voice, diabetes, osteoporosis and mesenchymal neoplasm in patient 2 . In both patients, we identified truncating null mutations affecting both alleles of WRN gene with loss of the nuclear localization signal. The homozygous p.Q748X WRN mutation of patient 1 was previously found in a Caucasian man diagnosed with Werner syndrome, but his clinical features were not reported [20], whereas patient 2 was affected by new WRN mutations. No evident genotype-phenotype correlations have been reported in Werner syndrome [20,39], although proximal truncation of WRN protein could lead to severe phenotypes [40]. Further studies are needed to eventually link the lipodystrophic clinical presentation to specific WRN mutations. However, our report shows that Werner syndrome is an important differential diagnosis in patients initially presenting with partial lipodystrophy as a prominent feature, leading to a specific follow-up, in particular regarding cancer risk, gynecology, and genetic counseling.

These two women presented with severe insulin resistance, with insulinemia being dramatically increased during OGTT without hypoglycemia. Low SHBG and adiponectin levels suggest a post-receptor insulin signalling defect, as observed in other lipodystrophic syndromes, where ectopic fat deposition, particularly in muscle and liver, is thought to play a major role in insulin resistance [41]. In accordance, our patients had also 


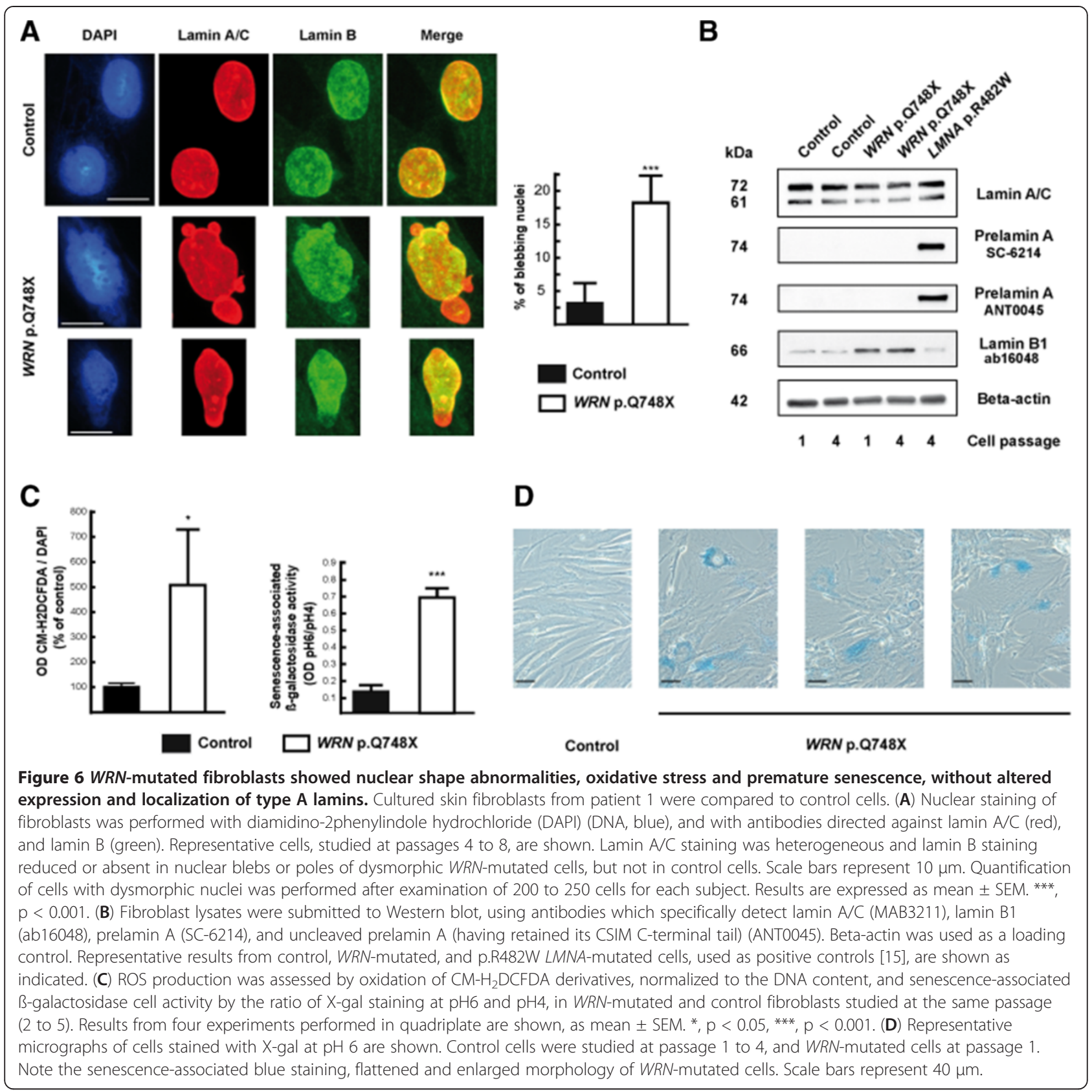

liver steatosis and hypertriglyceridemia. Their peripheral skinfolds confirmed a severe subcutaneous lipoatrophy of the limbs, whereas percentage of fat measured by DEXA in limbs was increased or only slightly decreased, suggesting that the limb muscles could be infiltrated with lipids. Insulin resistance has been previously reported in patients with Werner syndrome, with hypoadiponectinemia and increased intra-abdominal visceral fat in some patients $[42,43]$, but insulin values did not reach such dramatically elevated levels $[43,44]$. Therefore, our report suggests that the presence of a marked lipodystrophy can contribute to the severity of insulin resistance in Werner syndrome.

Our report also points out the specific gynecological and obstetrical complications of Werner syndrome. Hypogonadism is a classic sign of Werner syndrome, but its precise origin has not been investigated [20,38]. To our knowledge, only three pregnant women with clinicallysuspected, but not genetically-confirmed Werner syndrome, have been previously reported [23-26]. None of them carried their pregnancies to full-term, with spontaneous abortions at 10, 16 and 23 weeks [23], or preterm 
delivery at 25 to 34 weeks of gestation, due to cervical insufficiency in three cases $[23,24]$ or to caesarean section for maternal life-threatening ischemic heart disease in one case $[25,26]$. Preeclampsia occurred during two pregnancies, in the absence of diabetes [23], and placental vascular alterations were observed in one case [24]. Our two patients had experienced early spontaneous abortions and had reduced fertility. They both became pregnant during the follow-up, but severe cervical incompetence, which thus appears to be a frequent obstetrical complication in this disease, led to a preterm birth in one case, and to a second term-abortion in the other. No specific abnormality was evidenced in the foetus and the preterm newborn. Pancreatic islet hyperplasia observed at foetal autopsy was linked to gestational diabetes. The placenta showed signs of chorioamnionitis and funiculitis, which were secondary to premature rupture of membranes.

In these women, reduced fertility was probably related to a premature decrease in the pool of primordial ovarian follicles (diminished ovarian reserve). Indeed, although their menstrual cycles were not modified, and their FSH levels were still within normal range, indicating that they did not had premature ovarian failure, their AMH and inhibin B serum levels were very low [45]. Biological ovarian hyperandrogenism, observed in patient 2 , and polycystic ovaries in patient 1 , favored by extreme insulin resistance, could also have contributed to decreased fertility. In accordance, both pregnancies were obtained after reducing hyperinsulinemia with metformin treatment. Therefore, both insulin resistance and premature ovarian ageing could lead to decreased fertility in Werner syndrome.

Lipodystrophic and progeroid laminopathies are characterized by cellular senescence and nuclear dysmorphies, with nuclear blebs showing abnormal nuclear staining of A and B-type lamins [3,11,12,15,46]. Several studies have suggested that accumulation of farnesylated forms of prelamin A could underlie these abnormalities (for review, see [47]). Our present results show that fibroblasts with WRN null mutations present nuclear deformations similar to those observed in laminopathies, as described in one previous study [48]. We also showed that oxidative stress and cellular senescence were enhanced in WRN-mutated cells. However, prelamin A was not accumulated in $W R N$-mutated cells, suggesting that primary DNA repair defects and $L M N A$ alterations act by different mechanisms to induce premature ageing. In addition, although lamin B staining was decreased in nuclear blebs, the overall lamin B1 protein expression was increased in WRNmutated cells, which was not previously described in laminopathies. The role of B type-lamins in cellular senescence is complex [49]. Indeed, replicative or oncogeneinduced senescence has been linked to underexpression of lamin B1 [50], but oxidative stress-induced senescence to overexpression of lamin B1 [51]. An interesting hypothesis is that cellular stresses which alter the normal ratio of lamin B1 to functional lamin A, lead to deleterious changes in nuclear lamina, then senescence [49]. In accordance, and in line with our results, cells from patients with ataxia-telangiectasia, another genetic disease due to DNA damage signalling defects, display a state of endogenous oxidative stress which induces lamin B1 overexpression, nuclear shape alterations and senescence through MAP kinase activation [51]. It is possible that MAP kinase activation, which was previously observed in Werner syndrome [52], could also contribute to lamin B1-linked cellular senescence. Whether WRNlinked lipodystrophy could be secondary to primary mesenchymal cellular senescence, as it was suggested in laminopathies, needs to be further investigated.

\section{Conclusion}

This report points out that partial lipodystrophic syndrome with severe insulin resistance can reveal Werner syndrome due to WRN mutations. Therefore, the search for clinical and biological arguments in favor of this diagnosis is mandatory in patients with partial lipodystrophies. In addition to some clinical features that distinguish lipodystrophic syndromes due to $W R N$ as compared to LMNA mutations (as early cataracts and mesenchymal neoplasms), peculiar gynecological and obstetrical risk factors, i.e. diminished ovarian reserve and cervical incompetence, also characterize women with Werner syndrome. From a cellular point of view, this study shows that WRN mutations induce alterations in type B lamins expression and localization, with nuclear dysmorphies, that could participate to cellular senescence.

\begin{abstract}
Abbreviations
HGPS: Hutchinson-Gilford progeria; MAD: Mandibuloacral dysplasia; FPLD2: Familial partial lipodystrophy of the Dunnigan type; WS: Werner syndrome; OGTT: Oral glucose tolerance test; DAPI: 4',6'-di-amidine-2phenylindole dihydrochloride; ROS: Reactive oxygen species; CM-H2DCFDA derivatives: 5- (and 6)-chloromethyl-2',7'-dichlorodihydrofluorescein diacetate, acetyl ester; X-gal: 5-bromo-4-chloro-3-indolyl-ß-D-galactoside; BMl: Body mass index; ALT: Alanine transaminase; GGT: Gamma-glutamyl transferase; SHBG: Sex-hormone binding globulin; AMH: Anti-müllerian hormone; DEXA: Whole-body dual-energy X-ray absorptiometry.
\end{abstract}

\section{Competing interests}

The authors declare that they have no competing interests.

\section{Authors' contributions}

$\mathrm{BD}$ cared for one of the patients, analyzed the data, contributed to the discussion and drafted the manuscript. PD'A, MS, SO, GC, PB, PL, BC and SC$M$ cared for one of the patients, contributed to the discussion and reviewed the manuscript. MA carried out the cellular studies and contributed to the discussion, NU performed molecular analyses, contributed to the discussion and reviewed the manuscript. Y-JB performed molecular analyses, cared of one of the patient, contributed to the discussion and reviewed the manuscript. RG performed pathological analyses, contributed to the discussion and reviewed the manuscript. CV cared of the patients, analyzed the data, and wrote the manuscript. All authors read and approved the final manuscript. 


\section{Acknowledgements}

We thank the patients who participated in this study, Drs Jean-Philippe Bastard and Soraya Fellahi for leptin and adiponectin measurements, Dr Najiba Lahlou for anti-Müllerian hormone and inhibin B measurements, Dr Olivier Lascols for PPARG sequencing in patient 1, and Prof. Yves Menu and Drs Claude Levy and Serge Perot for magnetic resonance imaging. This work was supported by grants from Institut National de la Santé et de la Recherche Médicale (INSERM), Université Pierre et Marie Curie (UPMC) and Institute of Cardiometabolism and Nutrition [ICAN], grant no. ANR-10-IAHU.

\section{Author details}

${ }^{1}$ Assistance Publique-Hôpitaux de Paris (AP-HP), Hôpital Saint-Antoine, Endocrinologie, Diabétologie et Endocrinologie de la Reproduction, F-75012, Paris, France. ${ }^{2}$ Hôpital Henri Duffaut, Endocrinologie-Maladies Métaboliques, F-84902, Avignon, France. ${ }^{3}$ INSERM UMR_S938, Centre de Recherche SaintAntoine, F-75012, Paris, France. ${ }^{4}$ UPMC Univ Paris 6, UMR_S938, F-75005, Paris, France. ${ }^{5}$ ICAN Institute of Cardiometabolism and Nutrition, Groupe Hospitalier Universitaire La Pitié Salpêtrière, Paris, France. ${ }^{6}$ Centre Jean Perrin, Laboratoire de diagnostic génétique et moléculaire, F-63000,

Clermont-Ferrand, France. ${ }^{7}$ Centre Hospitalier de Nemours, Centre d'Evaluation et de Traitement de la Douleur, and EA 4391, Faculté de médecine, Université Paris-Est Créteil, F-77796, Nemours, France. ${ }^{8}$ Assistance Publique-Hôpitaux de Paris (AP-HP), Hôpital Armand-Trousseau, Génétique et Embryologie, F- 75012, Paris, France. ${ }^{9}$ Hôpital A. de Villeneuve, Pédiatrie néonatale, F-34295, Montpellier, France. ${ }^{10}$ Hôpital A. de Villeneuve, Gynéco-Obstétrique, F-34295, Montpellier, France. ${ }^{11}$ Centre de Référence de pathologie neuromusculaire Paris-Est, Groupe Hospitalier Pitié-Salpêtrière, APHP, F-75013, Paris, France. ${ }^{12}$ Assistance Publique-Hôpitaux de Paris (AP-HP), Hôpital Armand-Trousseau, Unité d'Obstétrique-Maternité, F-75012, Paris, France. ${ }^{13}$ INSERM U933, F-75012, Paris, France. ${ }^{14}$ AP-HP, Hôpital Tenon, Biochimie et Hormonologie, F-75020, Paris, France.

\section{Received: 27 March 2013 Accepted: 3 July 2013}

Published: 12 July 2013

\section{References}

1. De Sandre-Giovannoli A, Bernard R, Cau P, Navarro C, Amiel J, Boccaccio I, Lyonnet S, Stewart CL, Munnich A, Le Merrer M, Levy N: Lamin A truncation in Hutchinson-Gilford progeria. Science 2055, 2003:300.

2. Eriksson M, Brown WT, Gordon LB, Glynn MW, Singer J, Scott L, Erdos MR, Robbins CM, Moses TY, Berglund P, Dutra A, Pak E, Durkin S, Csoka AB, Boehnke M, Glover TW, Collins FS: Recurrent de novo point mutations in lamin A cause Hutchinson-Gilford progeria syndrome. Nature 2003, 423:293-298.

3. Novelli G, Muchir A, Sangiuolo F, Helbling-Leclerc A, D'Apice MR, Massart C, Capon F, Sbraccia P, Federici M, Lauro R, Tudisco C, Pallotta R, Scarano G, Dallapiccola B, Merlini L, Bonne G: Mandibuloacral dysplasia is caused by a mutation in LMNA-encoding lamin A/C. Am J Hum Genet 2002, 71:426-431.

4. Hennekam RC: Hutchinson-Gilford progeria syndrome: review of the phenotype. Am J Med Genet 2006, 140:2603-2624.

5. Cao H, Hegele RA: Nuclear lamin A/C R482Q mutation in canadian kindreds with Dunnigan-type familial partial lipodystrophy. Hum Mol Genet 2000, 9:109-112.

6. Shackleton $S$, Lloyd DJ, Jackson SN, Evans R, Niermeijer MF, Singh BM, Schmidt H, Brabant G, Kumar S, Durrington PN, Gregory S, O'Rahilly S, Trembath RC: $L M N A$, encoding lamin $A / C$, is mutated in partial lipodystrophy. Nat Genet 2000, 24:153-156.

7. Caux F, Dubosclard E, Lascols O, Buendia B, Chazouillères O, Cohen A, Courvalin JC, Laroche L, Capeau J, Vigouroux C, Christin-Maitre S: A new clinical condition linked to a novel mutation in lamins $A$ and $C$ with generalized lipoatrophy, insulin-resistant diabetes, disseminated leukomelanodermic papules, liver steatosis, and cardiomyopathy. J Clin Endocrinol Metab 2003, 88:1006-1013.

8. Chen L, Lee L, Kudlow BA, Dos Santos HG, Sletvold O, Shafeghati Y, Botha EG, Garg A, Hanson NB, Martin GM, Mian IS, Kennedy BK, Oshima J: LMNA mutations in atypical Werner's syndrome. Lancet 2003, 362:440-445.

9. Csoka AB, Cao H, Sammak PJ, Constantinescu D, Schatten GP, Hegele RA: Novel lamin $A / C$ gene (LMNA) mutations in atypical progeroid syndromes. J Med Genet 2004, 41:304-308.
10. Garg A, Subramanyam L, Agarwal AK, Simha V, Levine B, D'Apice MR, Novelli $\mathrm{G}$, Crow Y: Atypical progeroid syndrome due to heterozygous missense LMNA mutations. J Clin Endocrinol Metab 2009, 94:4971-4983.

11. Vigouroux C, Auclair M, Dubosclard E, Pouchelet M, Capeau J, Courvalin JC, Buendia B: Nuclear envelope disorganization in fibroblasts from lipodystrophic patients with heterozygous $\mathrm{R} 482 \mathrm{Q} / \mathrm{W}$ mutations in the lamin A/C gene. J Cell Sci 2001, 114:4459-4468.

12. Goldman RD, Shumaker DK, Erdos MR, Eriksson M, Goldman AE, Gordon LB, Gruenbaum Y, Khuon S, Mendez M, Varga R, Collins FS: Accumulation of mutant lamin A causes progressive changes in nuclear architecture in Hutchinson-Gilford progeria syndrome. Proc Natl Acad Sci USA 2004, 101:8963-8968.

13. Burtner CR, Kennedy BK: Progeria syndromes and ageing: what is the connection? Nat Rev Mol Cell Biol 2010, 11:567-578.

14. Capanni C, Mattioli E, Columbaro M, Lucarelli E, Parnaik VK, Novelli G, Wehnert M, Cenni V, Maraldi NM, Squarzoni S, Lattanzi G: Altered pre-lamin A processing is a common mechanism leading to lipodystrophy. Hum Mol Genet 2005, 14:1489-1502.

15. Caron M, Auclair M, Donadille B, Béréziat V, Guerci B, Laville M, Narbonne H, Bodemer C, Lascols O, Capeau J, Vigouroux C: Human lipodystrophies linked to mutations in A-type lamins and to HIV protease inhibitor therapy are both associated with prelamin A accumulation, oxidative stress and premature cellular senescence. Cell Death Differ 2007, 14:1759-1767.

16. Liu B, Wang J, Chan KM, Tjia WM, Deng W, Guan X, Huang JD, Li KM, Chau PY Chen DJ, Pei D, Pendas AM, Cadinanos J, Lopez-Otin C, Tse HF, Hutchison C, Chen J, Cao Y, Cheah KS, Tryggvason K, Zhou Z: Genomic instability in laminopathy-based premature aging. Nat Med 2005, 11:780-785

17. Shumaker DK, Dechat T, Kohlmaier A, Adam SA, Bozovsky MR, Erdos MR, Eriksson M, Goldman AE, Khuon S, Collins FS, Jenuwein T, Goldman RD: Mutant nuclear lamin A leads to progressive alterations of epigenetic control in premature aging. Proc Natl Acad Sci USA 2006, 103:8703-8708.

18. Zhang J, Lian Q, Zhu G, Zhou F, Sui L, Tan C, Mutalif RA, Navasankari R, Zhang Y, Tse HF, Stewart CL, Colman A: A human iPSC model of Hutchinson Gilford Progeria reveals vascular smooth muscle and mesenchymal stem cell defects. Cell Stem Cell 2011, 8:31-45.

19. Gray MD, Shen JC, Kamath-Loeb AS, Blank A, Sopher BL, Martin GM, Oshima J, Loeb LA: The Werner syndrome protein is a DNA helicase. Nat Genet 1997, 17:100-103.

20. Huang S, Lee L, Hanson NB, Lenaerts C, Hoehn H, Poot M, Rubin CD, Chen DF, Yang CC, Juch H, Dorn T, Spiegel R, Oral EA, Abid M, Battisti C, LucciCordisco E, Neri G, Steed EH, Kidd A, Isley W, Showalter D, Vittone JL, Konstantinow A, Ring J, Meyer P, Wenger SL, von Herbay A, Wollina U, Schuelke $M$, Huizenga $C R$, et al: The spectrum of WRN mutations in Werner syndrome patients. Hum Mutat 2006, 27:558-567.

21. Vantyghem MC, Vincent-Desplanques D, Defrance-Faivre F, Capeau J, Fermon C, Valat AS, Lascols O, Hecart AC, Pigny P, Delemer B, Vigouroux C, Wemeau JL: Fertility and obstetrical complications in women with LMNA-related familial partial lipodystrophy. J Clin Endocrinol Metab 2008, 93:2223-2229

22. Joy TR, Hegele RA: Prevalence of reproductive abnormalities among women with familial partial lipodystrophy. Endocr Pract 2008, 14:1126-1132.

23. Ogawa M, Nagata H, Koyanagi T: Pregnancy complicated by Werner syndrome. Obstet Gynecol 1996, 88:722.

24. Murakami M, Tsutsumi S, Tezuka N, Kurachi H: Pregnancy complicated by Werner's syndrome. Bjog 2003, 110:635-636.

25. Torbé A, Czajka R, Gutowska-Czajka D, Sipak-Szmigiel O, Ronin-Walknowska E, Andrysiak-Mamos E, Syrenicz A: Successful outcome of pregnancy complicated by Werner's syndrome. J Matern Fetal Neonatal Med 2010, 23:1056-1058

26. Solek-Pastuszka J, Zagrodnik-Ulan E, Plonka T, Wylot M, Biernawska J, Bohatyrewicz R, Kos W, Zukowski M, Celewicz Z: Pregnancy complicated by Werner syndrome. Acta Obstet Gynecol Scand 2011, 90:201-202.

27. Dominici S, Fiori V, Magnani M, Schena E, Capanni C, Camozzi D, D'Apice MR, Le Dour C, Auclair M, Caron M, Novelli G, Vigouroux C, Maraldi NM, Lattanzi G: Different prelamin A forms accumulate in human fibroblasts: a study in experimental models and progeria. Eur J Histochem 2009, 53:43-52.

28. Chaudhary N, Courvalin JC: Stepwise reassembly of the nuclear envelope at the end of mitosis. J Cell Biol 1993, 122:295-306.

29. Garg A, Vinaitheerthan M, Weatherall PT, Bowcock AM: Phenotypic heterogeneity in patients with familial partial lipodystrophy (Dunnigan 
variety) related to the site of missense mutations in lamin $\mathrm{A} / \mathrm{C}$ gene. $J$ Clin Endocrinol Metab 2001, 86:59-65.

30. Araujo-Vilar D, Loidi L, Dominguez F, Cabezas-Cerrato J: Phenotypic gender differences in subjects with familial partial lipodystrophy (Dunnigan variety) due to a nuclear lamin A/C R482W mutation. Horm Metab Res 2003, 35:29-35.

31. Mazess RB, Barden HS, Bisek JP, Hanson J: Dual-energy x-ray absorptiometry for total-body and regional bone-mineral and soft-tissue composition. Am J Clin Nutr 1990, 51:1106-1112.

32. Garg A: Lipodystrophies: genetic and acquired body fat disorders. J Clin Endocrinol Metab 2011, 96:3313-3325.

33. Vigouroux C, Caron-Debarle M, Le Dour C, Magré J, Capeau J: Molecular mechanisms of human lipodystrophies: from adipocyte lipid droplet to oxidative stress and lipotoxicity. Int J Biochem Cell Biol 2011, 43:862-876.

34. Huang-Doran I, Sleigh A, Rochford JJ, O'Rahilly S, Savage DB: Lipodystrophy: metabolic insights from a rare disorder. J Endocrinol 2010, 207:245-255.

35. Lloyd DJ, Trembath RC, Shackleton S: A novel interaction between lamin A and SREBP1: implications for partial lipodystrophy and other laminopathies. Hum Mol Genet 2002, 11:769-777.

36. Caron M, Auclair M, Sterlingot H, Kornprobst M, Capeau J: Some HIV protease inhibitors alter lamin $\mathrm{A} / \mathrm{C}$ maturation and stability, SREBP-1 nuclear localization and adipocyte differentiation. AIDS 2003, 17:2437-2344.

37. Duband-Goulet I, Woerner S, Gasparini S, Attanda W, Konde E, Tellier-Lebegue C, Craescu CT, Gombault A, Roussel P, Vadrot N, Vicart P, Ostlund C, Worman HJ, Zinn-Justin S, Buendia B: Subcellular localization of SREBP1 depends on its interaction with the C-terminal region of wildtype and disease related A-type lamins. Exp Cell Res 2011, 317:2800-2813.

38. Takemoto M, Mori S, Kuzuya M, Yoshimoto S, Shimamoto A, Igarashi M, Tanaka Y, Miki T, Yokote K: Diagnostic criteria for Werner syndrome based on Japanese nationwide epidemiological survey. Geriatr Gerontol Int 2012. Jul 23 (Epub ahead of print).

39. Uhrhammer NA, Lafarge L, Dos Santos L, Domaszewska A, Lange M, Yang Y, Aractingi $S$, Bessis $D$, Bignon $Y$ J: Werner syndrome and mutations of the WRN and LMNA genes in France. Hum Mutat 2006, 27:718-719.

40. Vidal V, Bay JO, Champomier F, Grancho M, Beauville L, Glowaczower C, Lemery D, Ferrara M, Bignon YJ: The 1396del A mutation and a missense mutation or a rare polymorphism of the WRN gene detected in a French Werner family with a severe phenotype and a case of an unusual vulvar cancer. Hum Mutat 1998, 11:413-414.

41. Semple RK, Cochran EK, Soos MA, Burling KA, Savage DB, Gorden P, O'Rahilly S: Plasma adiponectin as a marker of insulin receptor dysfunction: clinical utility in severe insulin resistance. Diabetes Care 2008, 31:977-979.

42. Yokote K, Hara K, Mori S, Kadowaki T, Saito Y, Goto M: Dysadipocytokinemia in Werner syndrome and its recovery by treatment with pioglitazone. Diabetes Care 2004, 27:2562-2563.

43. Mori S, Murano S, Yokote K, Takemoto M, Asaumi S, Take A, Saito Y: Enhanced intra-abdominal visceral fat accumulation in patients with Werner's syndrome. Int J Obes Relat Metab Disord 2001, 25:292-295.

44. Imura H, Nakao Y, Kuzuya H, Okamoto M, Yamada K: Clinical, endocrine and metabolic aspects of the Werner syndrome compared with those of normal aging. Adv Exp Med Biol 1985, 190:171-185.

45. Ledger WL: Clinical utility of measurement of anti-mullerian hormone in reproductive endocrinology. J Clin Endocrinol Metab 2010, 95:5144-5154.

46. Decaudain A, Vantyghem MC, Guerci B, Hecart AC, Auclair M, Reznik Y, Narbonne H, Ducluzeau PH, Donadille B, Lebbé C, Béréziat V, Capeau J, Lascols O, Vigouroux C: New metabolic phenotypes in laminopathies: LMNA mutations in patients with severe metabolic syndrome. J Clin Endocrinol Metab 2007, 92:4835-4844.

47. Worman H: J Nuclear lamins and laminopathies. J Pathol 2012, 226:316-325.

48. Adelfalk C, Scherthan H, Hirsch-Kauffmann M, Schweiger M: Nuclear deformation characterizes Werner syndrome cells. Cell Biol Int 2005, 29:1032-1037.

49. Hutchison CJ: B-type lamins and their elusive roles in metazoan cell proliferation and senescence. EMBO J 2012, 31:1058-1059.

50. Shimi T, Butin-lsraeli V, Adam SA, Hamanaka RB, Goldman AE, Lucas CA Shumaker DK, Kosak ST, Chandel NS, Goldman RD: The role of nuclear lamin B1 in cell proliferation and senescence. Genes Dev 2011, 25:2579-2593.
51. Barascu A, Le Chalony C, Pennarun G, Genet D, Imam N, Lopez B, Bertrand $P$ : Oxidative stress induces an ATM-independent senescence pathway through p38 MAPK-mediated lamin B1 accumulation. EMBO J 2012, 31:1080-1094

52. Tivey HS, Brook AJ, Rokicki MJ, Kipling D, Davis T: p38 (MAPK) stress signalling in replicative senescence in fibroblasts from progeroid and genomic instability syndromes. Biogerontology 2013, 14:47-62.

doi:10.1186/1750-1172-8-106

Cite this article as: Donadille et al.: Partial lipodystrophy with severe insulin resistance and adult progeria Werner syndrome. Orphanet Journal of Rare Diseases 2013 8:106.

\section{Submit your next manuscript to BioMed Central and take full advantage of:}

- Convenient online submission

- Thorough peer review

- No space constraints or color figure charges

- Immediate publication on acceptance

- Inclusion in PubMed, CAS, Scopus and Google Scholar

- Research which is freely available for redistribution 